\title{
PALM GAMMA-TOCOTRIENOL SUPPLEMENTATION SUPPRESS TUMOUR GROWTH AND METASTASIS IN A SYNGENEIC MOUSE MODEL OF BREAST CANCER
}

\author{
SHONIA SUBRAMANIAM ${ }^{1,2}$; AMMU KUTTY RADHAKRISHNAN ${ }^{3}$; JEYA SEELA ANANDHA RAO ${ }^{4}$; \\ PREMDASS RAMDAS ${ }^{5}$; NG MEI HAN ${ }^{2}$; METHIL KANNAN KUTTY ${ }^{6}$ and KANGA RANI SELVADURAY ${ }^{*}$
}

\begin{abstract}
Gamma-tocotrienol ( $\gamma \mathrm{T} 3)$ is an isoform of vitamin E found abundantly in palm oil, which is reported to possess antioxidant and anticancer activities. However, the immune-modulating properties of $\gamma$ T3 have yet to be elucidated. Breast cancer $(B C)$ was induced in female BALB/c mice by injecting $4 T 1$ murine mammary cancer cells into their mammary fat pads. When the tumour was palpable, the animals were randomly assigned into two groups: (i) control [fed twice daily with $50 \mu \mathrm{l}$ vehicle (soy oil)] or (ii) experimental (fed twice daily with $50 \mu \mathrm{l}$ of $0.5 \mathrm{mg}$ of $\gamma \mathrm{T} 3$ ). Results show that mice fed with $\gamma \mathrm{T} 3 \mathrm{~h}$ ad reduced tumour growth and metastasis. However, there are no marked changes in the percentages of peripheral blood leukocytes and cytokines production in these animals. Immunohistochemistry using antibodies to murine CD4, IL12R $\beta 2$, IL24 and FoxP3 on tumour sections from $\gamma \mathrm{T} 3$ treated mice suggested that $\gamma \mathrm{T} 3$ induced suppression of tumour growth and metastasis as well as reduced immunosuppression in the tumour microenvironment. It can be concluded that, $\gamma \mathrm{T} 3$ has the potential to suppress tumour growth and metastasis in this model. Further investigation on the host immune response is possible by prolonging treatment duration against $B C$.
\end{abstract}

Keywords: breast cancer, gamma-tocotrienol, mouse, supplementation, 4T1.

Received: 1 March 2021; Accepted: 28 September 2021; Published online: 22 November 2021.

\section{INTRODUCTION}

Breast cancer $(\mathrm{BC})$ is ranked as the most frequent cancer among women worldwide; with an

1 Faculty School of Postgraduate Studies,

International Medical University, 126, Jalan Jalil Perkasa 19, Bukit Jalil, 57000 Kuala Lumpur, Malaysia.

2 Malaysian Palm Oil Board,

6 Persiaran Institusi, Bandar Baru Bangi,

43000 Kajang, Selangor, Malaysia.

3 Jeffery Cheah School of Medicine,

Monash University Malaysia, Jalan Lagoon Selatan,

Bandar Sunway, 47500 Subang Jaya, Selangor, Malaysia.

4 Pathology Division, School of Medicine,

International Medical University, 126, Jalan Jalil Perkasa 19,

Bukit Jalil, 57000 Kuala Lumpur, Malaysia.

5 Applied Biomedical Sciences and Biotechnology, School of Health Sciences, International Medical University, 126, Jalan Jalil Perkasa 19, Bukit Jalil,

57000 Kuala Lumpur, Malaysia.

6 Faculty of Medicine, Lincoln University 2, Jalan Stadium SS 7/15, SS 7, 47301 Petaling Jaya, Selangor, Malaysia.

* Corresponding author e-mail: krani@mpob.gov.my estimated $11.6 \%$ new cases as reported in the global cancer statistics 2018 (Bray et al., 2018). According to the Malaysian National Cancer Registry (20122016) report (Azizah et al., 2019), one in 20 women may develop $B C$ in their lifetime and the incidence of $\mathrm{BC}$ was highest in Chinese, followed by Indians and Malays (Azizah et al., 2019). The mean age standardised rate (ASR) amongst Malaysian women who developed BC was reported to be 39.3 per 100000 populations in 2006 (Azizah et al., 2019). The survival rate of patients with $\mathrm{BC}$ is considered crucial as it can control the mortality rate; and in Malaysia, the 5-year survival rate was found to be favourably improved (Abdullah et al., 2013). Use of alternative medicine, particularly dietary supplements were reported to be common practices among Malaysian BC survivors (Shaharudin et al., 2011).

Bioactive compounds derived from natural sources are preferred compared to synthetic medicinal products as these have lesser sideeffects. One such compound is tocotrienols (T3), 
a natural isoform of vitamin E, which is found abundantly in palm oil and widely known for its anticancer, antioxidant and other beneficial health effects (Kabir et al., 2017; Montagnani Marelli et al., 2019). Vitamin $\mathrm{E}$ is divided into two families, namely tocopherol and T3. Major sources of dietary tocopherols are wheat-germ oil, safflower-seed oil, maize oil, soybean oil, whilst T3 can be found abundantly in palm oil, rice-bran oil and palm kernel oil. Both tocopherols and T3 exist naturally as four analogues i.e., alpha $(\alpha)$, beta $(\beta)$, delta $(\delta)$ and gamma $(\gamma)$. Vitamin E from palm oil is known as tocotrienol-rich fraction (TRF), which contains all four T3 analogues and alpha-tocopherol (Mba et al., 2015). There is increasing evidence suggesting T3s are potent antioxidants, which can potentially protect against various diseases, including cancer (Abraham et al., 2019; Montagnani Marelli et al., 2019). Evidence from cell-based studies have shown that T3 can inhibit growth and proliferation of various cancer cell lines (Aggarwal et al., 2019; De Silva et al., 2016; Fontana et al., 2020; Ghanem et al., 2019; Nesaretnam et al., 1998). The ability of $\mathrm{T} 3$ to selectively inhibit the proliferation of cancer cells strongly support their anticancer potential. Furthermore, T3 is also credited for its immunemodulating activities in a syngeneic mouse model of BC. For instance, TRF supplementation was reported to induce cancer-specific immune responses in a syngeneic mouse model of BC (Hafid et al., 2010). Previous studies had shown that T3 can inhibit both the proliferation of 4T1 mouse mammary cancer cells and tumour growth (Selvaduray et al., 2010; Subramaiam et al., 2021).

The focus of this article is to investigate the effects of daily supplementation of gammatocotrienol $(\gamma \mathrm{T} 3)$ to inhibit tumour growth and exert immunomodulation in a syngeneic mouse model of BC. The findings from this preclinical study may be useful to predict and develop new treatment strategies using palm $\mathrm{T} 3$ to fight BC.

\section{MATERIALS AND METHOD}

\section{Cell Lines and Culture Conditions}

The 4T1 mouse mammary cancer cells were obtained from the American Tissue Culture Collection (ATCC) (ATCC, Rockville, USA) and cultured according to the protocol provided by the ATCC. The cells were cultured at $37^{\circ} \mathrm{C}$ in Roswell Park Memorial Institute Medium (RPMI) medium (GIBCO, Invitrogen, USA) supplemented with L-glutamine (GIBCO, Invitrogen, USA), 10\% fetal bovine serum (FBS) (GIBCO, Invitrogen, USA), and $1 \%$ penicillin-streptomycin (GIBCO, Invitrogen, USA) in a humidified incubator containing 5\% carbon dioxide $\left(\mathrm{CO}_{2}\right)$.

\section{Preparation of Treatment}

The $\gamma \mathrm{T} 3$ used in this study was obtained from the Malaysian Palm Oil Board (MPOB). The $\gamma \mathrm{T} 3$ was extracted from palm oil with a purity range of 95\%99\% (Maarasyid et al., 2014). The $\gamma \mathrm{T} 3$ was prepared fresh every day prior to feeding by dissolving $0.5 \mathrm{mg}$ of $\gamma \mathrm{T} 3$ in $50 \mu \mathrm{l}$ of soy oil, which served as the vehicle.

\section{Experimental Procedure}

Female BALB/c mice aged 5-6 weeks (Cheneur Suppliers, Malaysia) were housed at the animal holding facility (AHF), International Medical University (IMU). All experimental procedures were approved by the Joint Committee for Research and Ethics, IMU (IMU-R060-2010) and the study was conducted according to the IMU animal ethics guidelines. The mice were maintained at $25 \pm 2^{\circ} \mathrm{C}$ with 12:12 hr dark/light cycle and they had free access to commercial food pellets and water throughout the study period. After one-week of acclimatisation, six $(n=6)$ mice were sacrificed to collect baseline data. The remaining mice $(n=48)$ received an injection of $100 \mu \mathrm{l}$ of $4 \mathrm{~T} 1$ cells $(10000$ cells $/ \mathrm{ml}$ ) at their right thoracic mammary fat pad to induce BC (Selvaduray et al., 2010). Once tumour was palpable (day 14), the mice were randomly divided into vehicle and treatment groups. The animals in the vehicle group were fed with $50 \mu 1$ vehicle (soy oil) whilst the mice in the treatment group were fed with $50 \mu$ l of vehicle containing $0.5 \mathrm{mg} \gamma \mathrm{T} 3$ twice daily (morning and evening) for a period of 35 days by oral gavage. Throughout the study period, six mice $(n=6)$ from each group were sacrificed every seven days (day 14, $21,28,35)$. Tumour size was monitored and measured weekly using a digital calliper. Tumour volume was calculated using the formula: $\mathrm{V}=0.52 \times \mathrm{L}^{2} \times \mathrm{W}(\mathrm{V}$ : volume, L: length and W: width) (Selvaduray et al., 2010). The study was terminated at day 35 when the tumour load in the vehicle group became too big and the animals started to show signs of distress. The animals were humanely euthanised using the cervical dislocation method.

\section{Histopathology Assessment}

At autopsy, tumour, lung, kidney and liver were removed and fixed in 10\% formalin for $48 \mathrm{hr}$ before it was processed using an automatic tissue processor (Leica TP1020 Automatic Tissue Processor, Leica, Germany). These tissues were paraffin-embedded and sectioned at $4 \mu \mathrm{m}$ thickness using a rotary microtome (Rotary Microtome, Leica, Germany). The tissue sections were stained with haematoxylin and eosin (H\&E) stains (Leica, Germany). The stained slides were evaluated by a pathologist using a light microscope (Nikon eclipse, Japan) to look for extent and signs of metastasis. 


\section{Immunohistochemistry Staining}

Tumours sections taken from vehicle-fed and $\gamma \mathrm{T} 3$-fed mice were incubated at room temperature with respective primary antibodies for $1 \mathrm{hr}$. The primary antibodies used were (i) anti-CD4 [rabbit anti-mouse CD4 polyclonal antibody (Dako, Denmark); (ii) anti-Forkhead box P3 (FoxP3) [rabbit anti-mouse FoxP3 polyclonal antibody] (Dako, Denmark); (iii) anti-interleukin-24 (IL-24) [rabbit anti-mouse IL-24 polyclonal antibody] (Dako, Denmark) and (iv) anti-interleukin-12-beta-2 receptor (IL-12R $\beta 2$ ) [rabbit anti-mouse IL-12R $\beta 2$ polyclonal antibody] (Dako, Denmark). After $1 \mathrm{hr}$, the slides were washed with a wash buffer and incubated for $20 \mathrm{~min}$ at room temperature with a biotinylated secondary antibody [biotinylated antirabbit polyclonal antibody] (Dako, Denmark)]. Following this, the slides were washed and incubated at room temperature for $20 \mathrm{~min}$ with streptavidin-conjugated horseradish peroxidase (HRP) (Dako, Denmark). After the slides were washed, a substrate chromogen (Dako, Denmark) was added to the sections and the slides were incubated at room temperature for an additional $20 \mathrm{~min}$. Following this, the slides were counterstained with haematoxylin and viewed under a light microscope. Staining intensity was determined using a semi-quantitative method of Allred scoring system (Fedchenko and Reifenrath, 2014), whereby the percentage of stained cells and intensity of staining were calculated. Each section was given a score based on the staining pattern $(0=$ negative, $1=$ weak, $2=$ moderate and $3=$ strong).

\section{Leucocyte Subsets}

At autopsy, blood was obtained via cardiac puncture and collected into heparinised tubes. The blood was centrifuged (200 $\mathrm{g}$ for $10 \mathrm{~min}$ at $4^{\circ} \mathrm{C}$ ) to separate plasma and cells. Once the plasma was removed, the red blood cells (RBC) were lysed by adding $2 \mathrm{ml}$ of RBC lysis buffer (BD Pharm Lyse, USA) and the leucocytes were recovered by centrifugation (200 $\mathrm{g}$ for $5 \mathrm{~min}$ at $4^{\circ} \mathrm{C}$ ). Then, the leucocytes were washed with cold phosphate-buffered saline (PBS) and recovered by centrifugation. Following this, the cells were resuspended in a staining buffer (FACS Sheath Fluid BD, USA) and counted. Cell count was adjusted to $1 \times 10^{6} / 100 \mu \mathrm{l}$ cells. The cells were added to appropriately labelled tubes and stained with conjugated antibodies for flow cytometer analysis. The antibodies used were specific to murine (i) TCR $-\beta^{+} \mathrm{CD} 4^{+} \mathrm{CD} 8 \mathrm{~A}^{+}$to identify T-lymphocytes (Biosciences BD, USA); (ii) CD335 ${ }^{+} \mathrm{CD} 3 \mathrm{e}^{-\mathrm{CD}} 49 \mathrm{~b}^{+}$ to detect natural killer (NK) cells (Biosciences $\mathrm{BD}, \mathrm{USA}$ ); and (iii) $\mathrm{CD} 4^{+} \mathrm{CD} 25^{+} \mathrm{FR}-4^{+}$to identify
T-regulatory (Treg) cells (Biosciences BD, USA). The cells were stained for $20 \mathrm{~min}$ at room temperature in the dark. Following this, the cells were washed with a staining buffer and recovered by centrifugation. The stained cells were resuspended in $0.5 \mathrm{ml}$ of cell fix buffer (Cell Fix BD, USA) and analysed using a multicolour flow cytometer (FACS Calibur, Becton-Dickson, USA). Data was collected using the Cell Quest software provided by the manufacturer (Becton Dickinson, USA). In each acquisition, 10000 cells were collected for data analysis.

\section{Quantification of Cytokines}

When the animals were sacrificed, the spleen from each animal was aseptically removed and a splenocyte suspension was prepared. The cells were counted and plated in a 96-well plate at a cell density of $5 \times 10^{3}$ splenocytes/well. The plates were incubated at $37^{\circ} \mathrm{C}$ in a humidified incubator with $5 \% \mathrm{CO}_{2}$. Then, $100 \mu \mathrm{l}$ of $4 \mathrm{~T} 1$ murine mammary cancer cells that have been pre-treated with $25 \mu \mathrm{g} \mathrm{ml}^{-1}$ mitomycin C (MMC) (Sigma-Aldrich, USA) for $2 \mathrm{hr}$ were added to the wells containing the freshly plated splenocytes. The plate was incubated at $37^{\circ} \mathrm{C}$ for $72 \mathrm{hr}$ in a humidified $5 \%$ $\mathrm{CO}_{2}$ incubator. After $72 \mathrm{hr}$, the splenocytes were harvested into $1.5 \mathrm{ml}$ tubes and centrifuged (200 g for $10 \mathrm{~min}$ at $4^{\circ} \mathrm{C}$ ). The culture supernatant from each sample was collected and stored at $-80^{\circ} \mathrm{C}$ prior to quantification of interferon gamma (IFN- $\gamma$ ) and transforming growth factor $\beta$ (TGF- $\beta$ ) using commercial READY SET GO! enzyme-linked immunosorbent assay (ELISA) kits as recommended by the manufacturer (eBiosciences, San Diego, Inc.).

\section{Statistical Analysis}

One-way analysis of variance (ANOVA) was performed using Statistical Package for Social Science (SPSS) version 16. The post-hoc Dunnett's test was used to compare data of experimental group against control groups. All data points are expressed as the mean \pm standard deviation (SD). A $p$-value of less than $0.05(p<0.05)$ was considered to be statistically significant.

\section{RESULTS AND DISCUSSION}

There was a significant delay in tumour progression on days 21 and 28 in mice fed with $\gamma \mathrm{T} 3$ compared to the vehicle-fed animals as shown by the tumour volume (Figure 1a) and tumour weight (Figure 1b) measurements. Histopathology findings on tumour sections from $\gamma$ T3-fed mice exhibited pleomorphic features with hyperchromatic nucleus 
and the presence of necrosis (Figure 2) whilst the breast tissues sections from the vehicle-fed mice showed poorly differentiated tumour and marked metastasis. In addition, sections obtained from the vital organs of animals fed with $\gamma \mathrm{T} 3$, such as the lung (Figure 3a), liver (Figure 3b) and kidney (Figure 3c) showed signs of minimal or delayed metastasis when compared to the vehicle-fed group. The lung tissue sections from both groups showed clusters of malignant (yellow circle) inflammatory (indicated with white circle) cells (Figure $3 a$ ). Sections of liver tissues from both groups also showed similar features (Figure $3 b$ ). However, sections of kidney tissue from both groups showed normal architecture with wellpreserved glomerular and tubular structures (red circle) (Figure 3c). However, the tissue sections from the liver and lungs from the vehicle-fed mice showed presence of multiple metastasis foci, which appear to have developed rapidly (Table 1). These findings suggest that $\gamma \mathrm{T} 3$ supplementation inhibited development and progression of $\mathrm{BC}$ as well as blocking the onset of metastasis. Previous studies have found that daily supplementation with TRF inhibited tumour growth and metastasis in this highly invasive syngeneic mouse model of BC (Abdul Hafid et al., 2013). Metastasis of tumour to distant organs has been associated with higher mortality (Ording et al., 2017) and in BC patients, tumour usually metastasises to theirlungs(Medeiros et al., 2019) causing further complication. Inhibition of tumour growth following $\gamma \mathrm{T} 3$ supplementation observed in this study is in agreement with our previous studies, where we had reported that daily supplementation of TRF inhibited tumour growth and metastasis in this syngeneic murine model of BC (Abdul Hafid et al., 2013; 2019; Selvaduray et al., 2010; Weng-Yew et al., 2009). Besides these evidence, recent studies also showed that $\gamma \mathrm{T} 3$ significantly suppressed proliferation and invasion of prostate (Fontana et al., 2020), gastrointestinal (Zhang et al., 2018), colon (Aggarwal et al., 2019; Wada et al., 2017) and liver (Aggarwal et al., 2019; Sazli et al., 2015) cancer cells. The underlying mechanism of how $\gamma \mathrm{T} 3$ suppresses tumour growth could be due to its anti-angiogenesis (Selvaduray et al., 2012), anti-proliferative (Nesaretnam et al., 1995) and anti-apoptotic (Srivastava and Gupta, 2006; $\mathrm{Wu}$ and $\mathrm{Ng}, 2010$ ) properties; which are well-documented in the literature. However, in the present study, we intent to investigate the involvement of CD4, FoxP3, IL-24, IL-12R $\beta 2$ in the $\gamma \mathrm{T} 3$ mediated suppression of tumour growth and metastases.

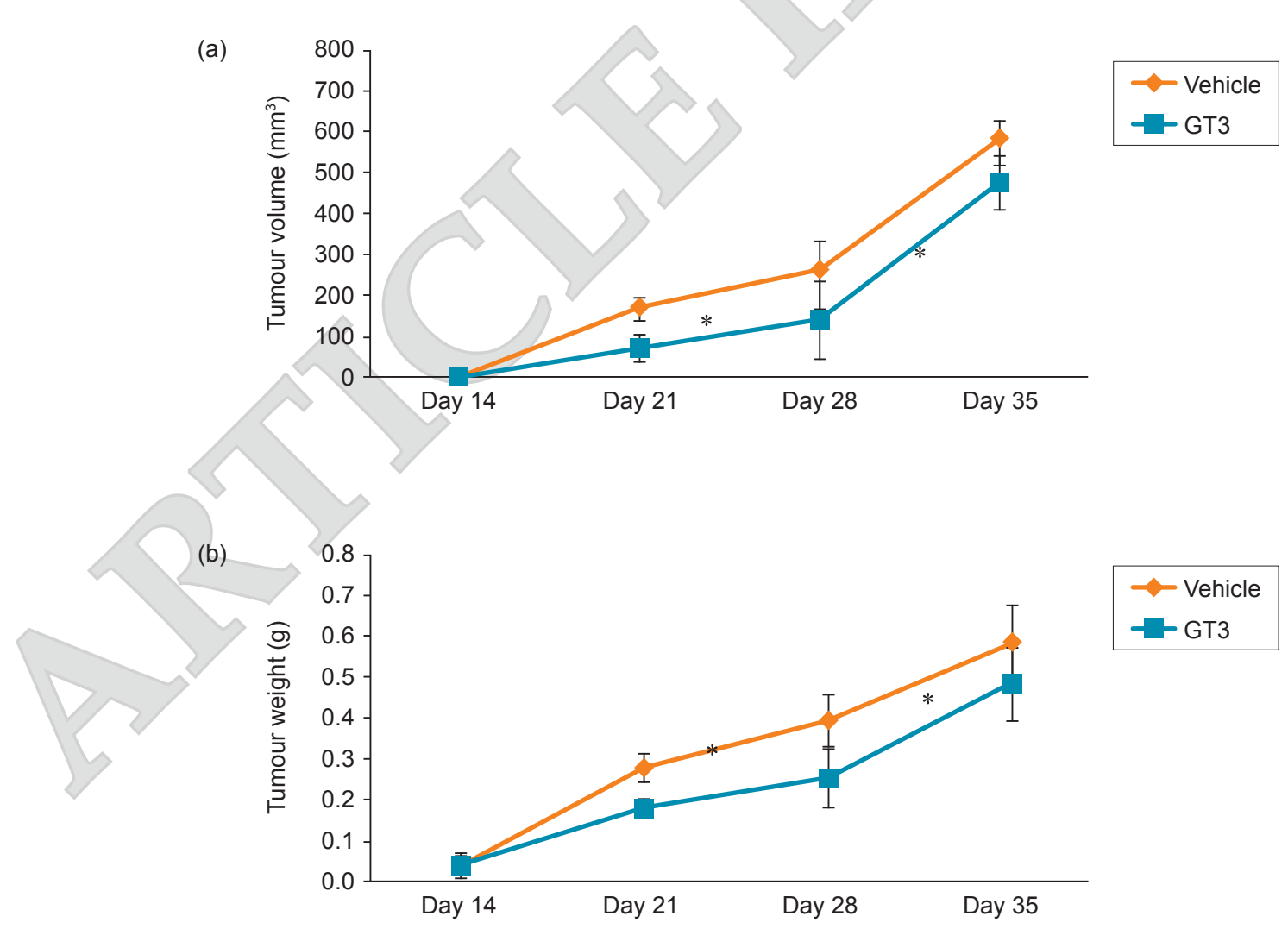

Note: Tumour volume and weight were measured once every seven days (days 14, 21, 28 and 35) using a digital calliper. Tumour volume $\left(\mathrm{mm}^{3}\right)$ was calculated using a formula that was previously described (Selvaduray et al., 2010). Tumour weight was measured by weighing the tumour at autopsy. Each data point represents mean $(n=6) \pm S D$. 
(a) Tumour sections from vehicle-fed mice

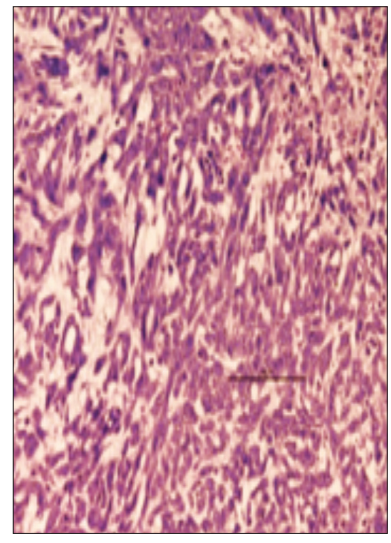

Day 21

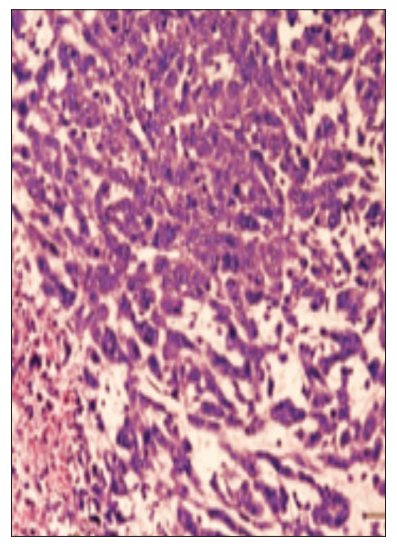

Day 28

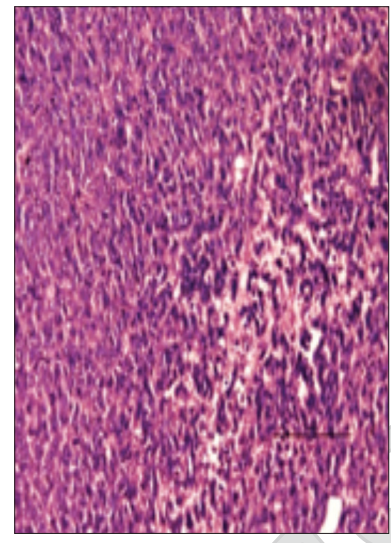

Day 35

(b) Tumour sections from GT3-fed mice

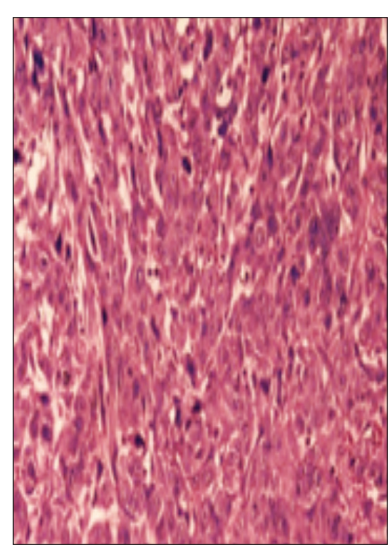

Day 21

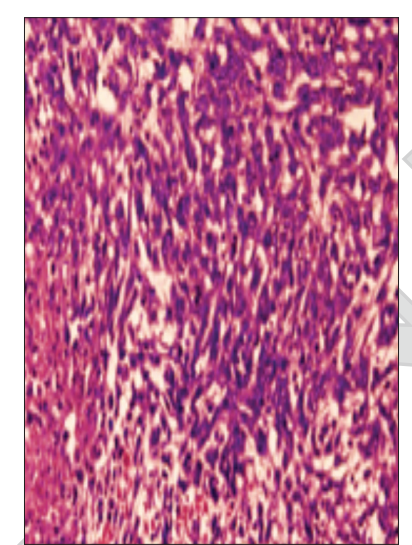

Day 28

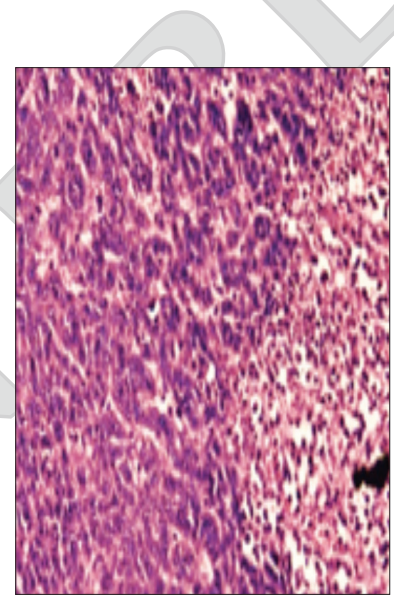

Day 35

Figure 2. Photomicrograph images (200X) of HEE stained sections of breast tumour tissues collected on day 21,28 and 35 from animals fed with vehicle or $\gamma T 3$ (GT3) groups.

\begin{tabular}{|c|c|c|c|c|}
\hline \multirow{2}{*}{ Groups } & \multirow{2}{*}{$\begin{array}{c}\text { Number of } \\
\text { mouse }\end{array}$} & \multirow{2}{*}{ Breast tumour differentiation } & \multicolumn{2}{|c|}{ Metastasis } \\
\hline & & & Lung & Liver \\
\hline \multirow[t]{6}{*}{ Vehicle } & 1 & Poorly differentiated & + & + \\
\hline & 2 & Poorly differentiated & + & + \\
\hline & 3 & Poorly differentiated & + & + \\
\hline & 4 & Poorly differentiated & + & + \\
\hline & 5 & Moderately differentiated & - & - \\
\hline & 6 & Moderately differentiated & - & - \\
\hline \multirow[t]{6}{*}{$\gamma \mathrm{T} 3$} & 1 & Necrosis & - & - \\
\hline & 2 & Moderately differentiated & + & - \\
\hline & 3 & Necrosis & - & - \\
\hline & 4 & Necrosis & - & - \\
\hline & 5 & Necrosis & - & - \\
\hline & 6 & Poorly differentiated & + & + \\
\hline
\end{tabular}

Note: The metastasis deposits in the lung and liver of vehicle and $\gamma \mathrm{T} 3$ groups were compared as present $(+)$ and absent $(-) .(p<0.05)$ for lung and liver. 
(a) Lungs
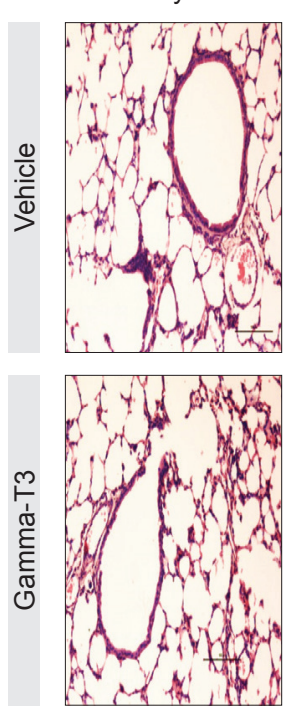

ar and
Day 14
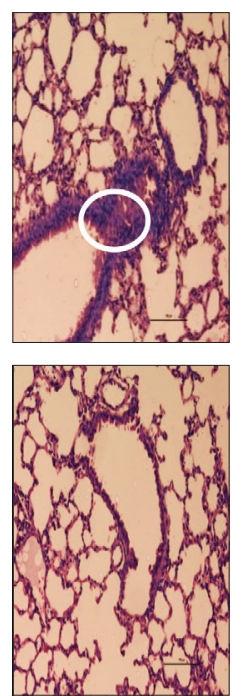

(b) Liver
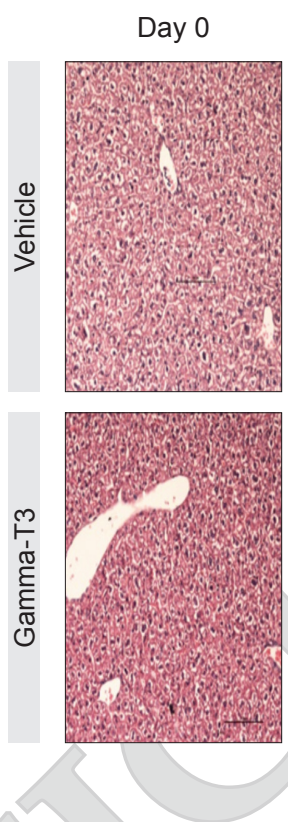

(c) Kidney
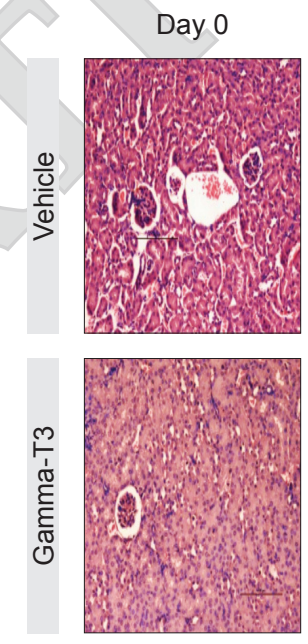

Day 14
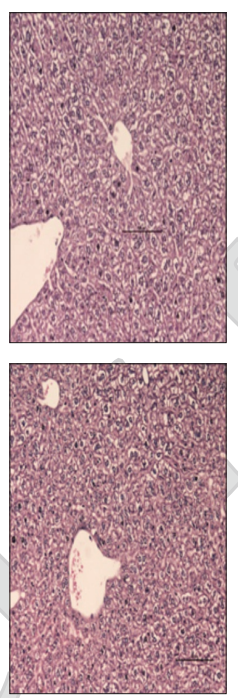

Day 14
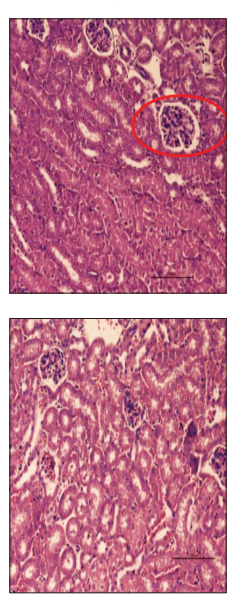

Day 21
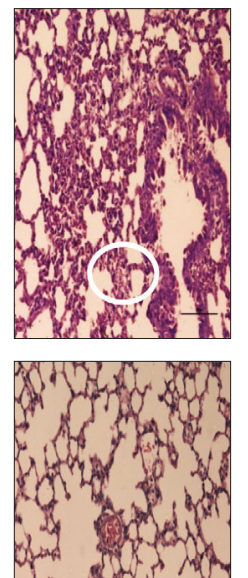

singeros

mones

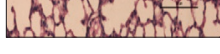

Day 28
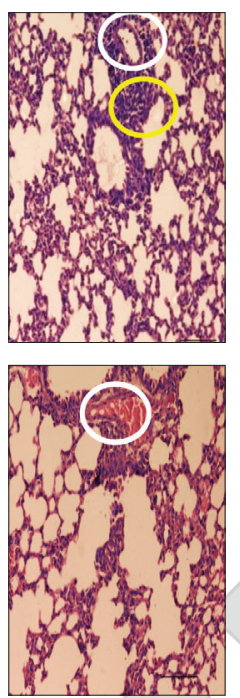

Day 28
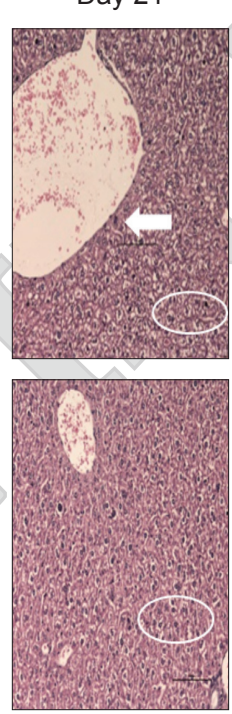

Day 21
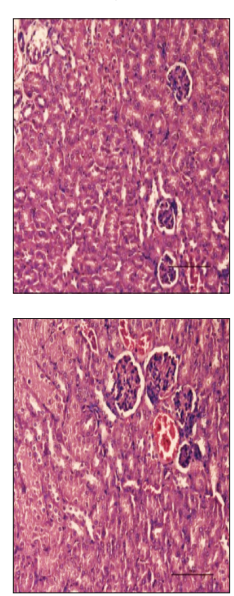
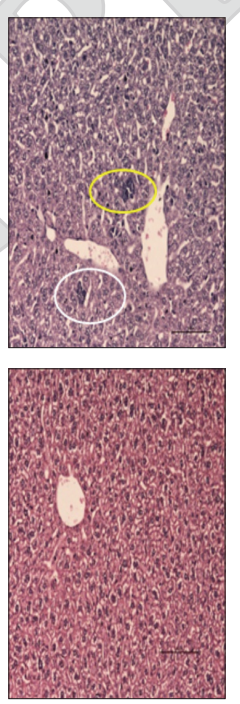

Day 28
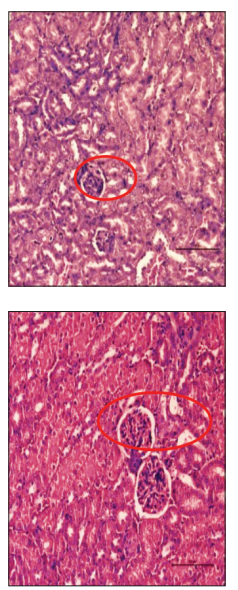

Day 35
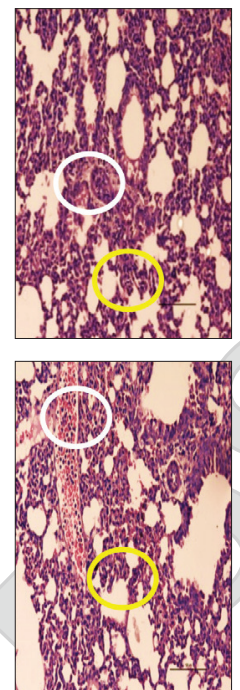

Day 35


Day 35


Note: Malignant cells indicated with yellow circle; inflammatory cells indicated with white circle.

Figure 3. Photomicrograph images (200X) of HEE stained (a) lungs; (b) liver and (c) kidney sections collected at autopsy on day $0,14,21,28$ and 35 days following tumour induction in mice fed with from vehicle or $\gamma$ T3 (GT3). 
CD4 is a cell surface glycoprotein found on surface of T-helper (Th) and Treg cells (Sambucci et al., 2019), which has high specificity to major histocompatibility complex class II (MHC II) proteins (Rzepecka et al., 2019). Activation of $\mathrm{CD}^{+}$ T-cells can result in differentiation of sub-types that facilitate immune regulation through secretion of certain cytokines. A previous study by Huang et al. (2015) suggested that $\mathrm{CD} 4^{+}$, along with $\mathrm{CD} 8^{+}$ T-cells are dynamically involved in the immune response against $\mathrm{BC}$, and that Th1 and $\mathrm{CD} 8^{+} \mathrm{T}$-cells were dominant populations in tumour-infiltrating lymphocytes involved in the immunosurveillance in the early stage of BC development. However, in the late cancer stage, the number of $\mathrm{CD} 4^{+}$tumourinfiltrating lymphocytes increased significantly and the Treg and Th17 cells become the dominant populations, which contribute to the tumour promotion. The high number of $\mathrm{CD} 4^{+} \mathrm{T}$-cells are most likely Treg cells, which also express this cell surface protein. High numbers of Treg cells are indicative of poor prognosis as these cells will create an immunosuppressive condition in the tumour microenvironment (Knochelmann et al., 2018; Ohue et al., 2019). Hence, tumour will be able to progress due to the compromised cell-mediated immunity and reduction in the T-cell populations. BC patients and experimental animals induced with BC with advanced cancer frequently report dysfunctions in the immune system, which is evident from the reduced $C D 4^{+}$ to $\mathrm{CD}^{+}$ratio $\left(\mathrm{CD}^{+}: \mathrm{CD}^{+}\right)$and decreased $\mathrm{T}$-cell proliferation possibly due to suppression by the Treg cells. In the present study, tumour tissue sections from $\gamma$ T3-fed mice showed higher number of $\mathrm{CD}^{+}$cells compared to tumour sections from vehicle-fed animals (Figure 4), suggestive of $\mathrm{CD} 4^{+}$

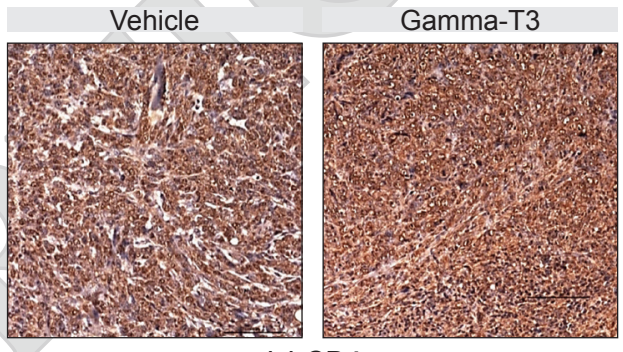

(a) CD4



(c) IL-12Rß2 associated anti-tumour immunity induced by $\gamma \mathrm{T} 3$. However, it should be noted that Treg cells also express the CD4 glycoprotein on the cell surface (Yu et al., 2012).

The transcription factor FoxP3 is a key biomarker that can be used to identify Treg cells (Tanaka and Sakaguchi, 2019). Tumour tissue sections from vehicle fed mice showed presence of high number of FoxP3 $3^{+}$cells (Figure 4). High number of $\mathrm{FoxP}^{+}$cells in tumour microenvironment is associated with suppression of host immune response, which in turn can allow tumour progression to take place (Sasidharan and Elkord, 2018; Verma et al., 2019). However, tumour sections from $\gamma \mathrm{T} 3$-fed mice showed marked reduction in the number of FoxP3 ${ }^{+}$cells (Figure 4). These findings suggest that $\gamma \mathrm{T} 3$ supplementation can facilitate the host immune system to suppress tumour progression by limiting the immunosuppressive tumour microenvironments.

Tumour sections from $\gamma$ T3-fed animals showed higher expression of IL-24 and IL-12R $\beta 2$ compared to sections from vehicle-fed mice (Figure 4), which supported presence of cell-mediated immunity. Interleukin-24 is cytokine linked with inhibition of tumour growth, anti-angiogenic and anti-metastasis activities (Panneerselvam et al., 2019; Zhang et al., 2019) whereby IL-12R $\beta 2$ together with IFN- $\gamma$ mediates differentiation of Th1 subset that plays crucial roles in cell-mediated immune responses, which include anticancer effects (Yamamoto et al., 1997). Statistical analysis using a semi-quantitative method confirmed that the difference observed on the expression of the four biomarkers (CD4, IL-24, IL-12 $\beta 2 R$ and FoxP3) in tumour tissues section from vehicle- or $\gamma \mathrm{T} 3$-fed mice were statistically significant $(p<0.05)$ (Figure 5).

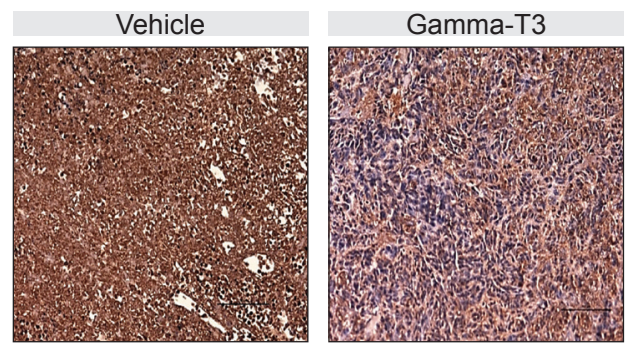

(b) FoxP3

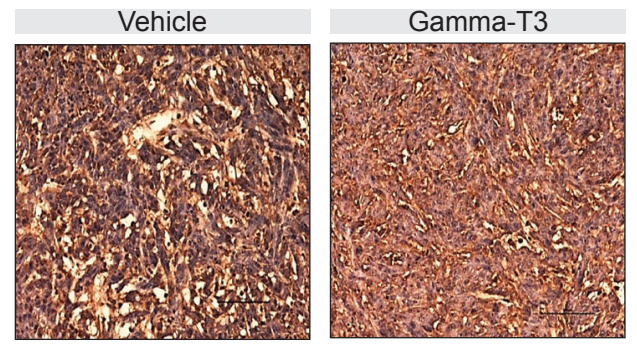

(d) IL-24

Figure 4. Photomicrograph images (200X) of breast tumour tissue sections from vehicle or $\gamma$ T3-fed mice stained with antibodies to murine (a) CD4, (b) FoxP3, (c) IL-12Rß2 and (d) IL-24 biomarkers analysed using immunohistochemistry. 


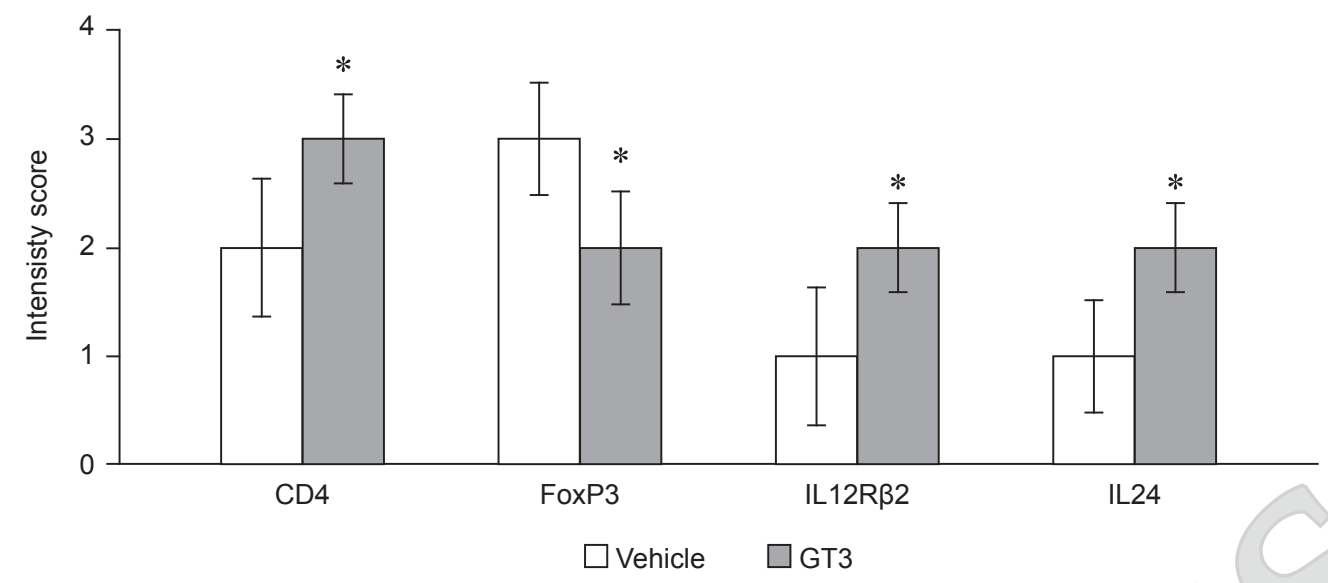

Note: This scoring system includes staining intensity and percentage of cells expressing these biomarkers. The results are expressed with an IHC score of $(0=$ negative, $1=$ weak, $2=$ moderate and $3=$ strong). Results expressed as a percentage \pm SD of six mice per group and $* p<0.05$ against vehicle group.

Figure 5. Immunohistochemistry staining of the four antibodies CD4, FoxP3, IL-12Rß2 and IL-24 on the tumour sections from vehicle or $\gamma$ T3 (GT3) - fed mice were scored using a semi-quantitative method i.e., Allred Scoring System.

There was no significant difference $(p>0.05)$ in the percentage of T-lymphocytes that express $\mathrm{CD}^{+}$ (TH) or $\mathrm{CD}^{+}$(cytotoxic T-lymphocytes) as well as NK cells in peripheral blood at any of the timepoints studied (Figure 6). There was a significant $(p<0.05)$ increase in the Treg cell population in peripheral blood from vehicle-fed mice on day 28 and day 35 (Figure 6). The increase in the number of Tregs appears to correlate with bigger tumour load (Figure 1). These findings support the results from the immunohistochemistry analysis, which showed reduction in $\mathrm{FoxP}^{+}$cells in the tumour tissue sections from $\gamma \mathrm{T} 3$ fed mice. This provided more evidence to support that $\gamma \mathrm{T} 3$ supplementation can modulate the host immune system in this syngeneic mouse model of BC.

However, it should be noted that $\gamma \mathrm{T} 3$ supplementation did not completely stop tumour progression. One of the reasons for this observation may be because $\gamma \mathrm{T} 3$ supplementation only started once the tumour is palpable. The syngeneic mouse model of BC used in this study is a highly tumourigenic model (Pulaski and OstrandRosenberg, 2000). Hence, intervention with $\gamma \mathrm{T} 3$ once tumour cells have been inoculated may give better results as this could trigger early activation of the host immune system to fight cancer. Another reason could be the low bioavailability of $\gamma \mathrm{T} 3$ in the blood as previous studies have found that oral $\gamma \mathrm{T} 3$ has low bioavailability due to low intestinal permeability (Abuasal et al., 2012).

Culture supernatant from mitogen-stimulated splenocytes from vehicle- and $\gamma \mathrm{T} 3$-fed mice showed significantly higher levels of IFN- $\gamma$ (Figure 7) when compared to baseline (day 0). However, there was no significant difference between the two study groups. IFN- $\gamma$ is the main regulator for TH1 immune response, which has a crucial role in controlling tumour growth (Alizadeh et al., 2021) whilst TGF- $\beta$ is a major cytokine that supports activities of Treg cells (Mikami et al., 2020), which play an important role in immunosuppression i.e., allow tumour progression. The lack of significant difference in the production of these cytokines between the two study groups may be attributed to the delay in starting the $\gamma \mathrm{T} 3$ intervention in this model. It is also possible that feeding $\gamma \mathrm{T} 3$ for a short duration may not be sufficient to activate host immune response to secrete sufficient cytokines to suppress the cancer. The syngeneic mouse model of $\mathrm{BC}$ used in the present study is a highly invasive and spontaneously metastatic model. Hence, short term feeding of $\gamma \mathrm{T} 3$ once tumour is palpable, may be insufficient to prepare the host immune system to control the tumour. Previous studies that have looked at effects of TRF supplementation in tumourinduced mice vaccinated with dendritic cell (DC) vaccines before (Abdul Hafid and Radhakrishnan, 2019; Abdul Hafid et al., 2013; Hafid et al., 2010) showed enhanced immune function and tumour suppression. However, it should be noted that in both these studies, the animals were supplemented with TRF for a longer period, which may have been sufficient to regulate the host immune system to fight against cancer.

To date, there has been only one study that investigated the effects of using TRF from palm oil in combination with tamoxifen in human BC patients (Nesaretnam et al., 2010). This study reported no association between adjuvant tocotrienol therapy and BC-specific survival in women with early BC, which has posed a setback to carry out more robust clinical trials in BC patients. More studies are needed to further evaluate the potential of using TRF as an anticancer agent in $\mathrm{BC}$ patients. 
(a)

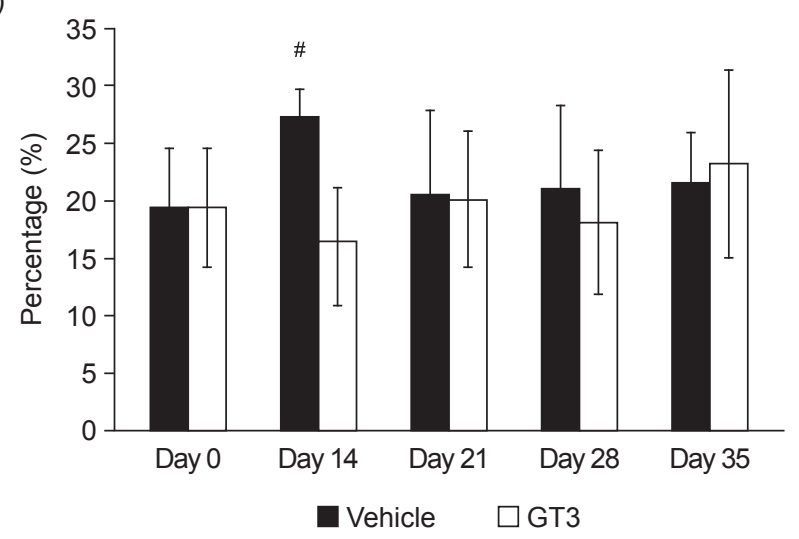

(c)

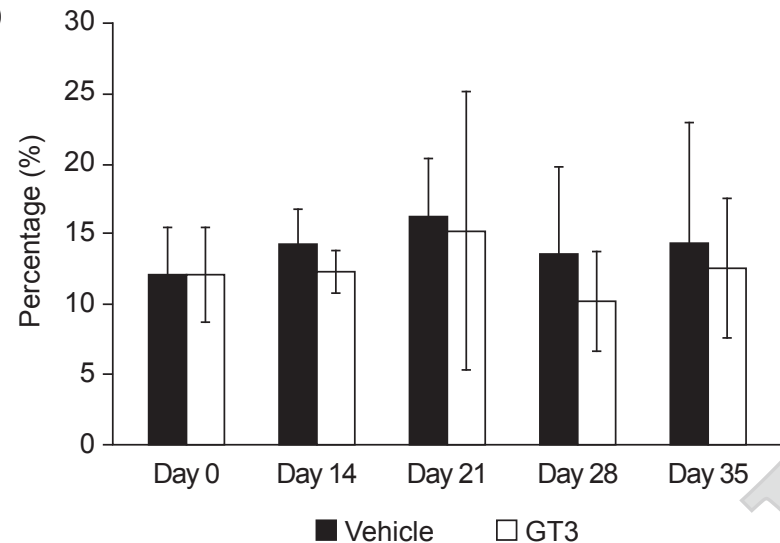

(b)

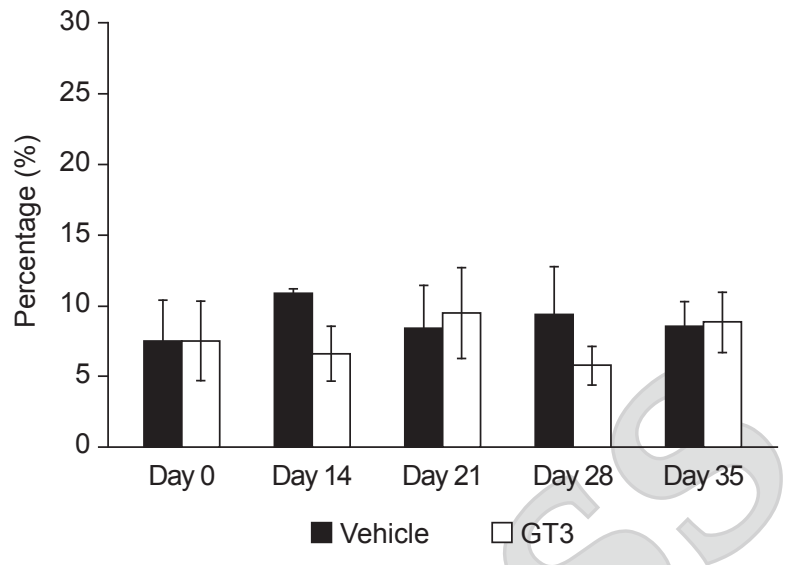

(d)

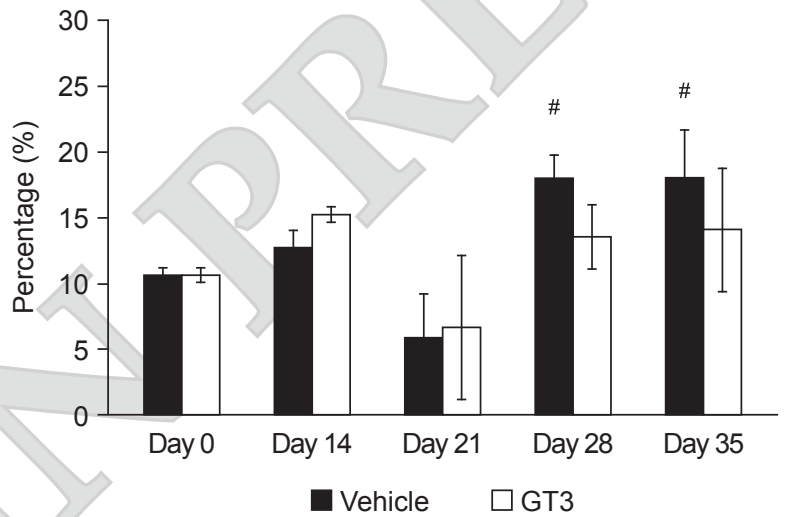

Note: Leucocytes were isolated from peripheral blood (vehicle or $\gamma \mathrm{T} 3$ (GT3)-fed mice) by via cardiac puncture and stained with fluorochrome-labelled antibodies to various murine cell surface proteins and analysed using a flow-cytometer. Data was collected using the Cell Quest software provided by the manufacturer (Becton Dickinson, USA). In each acquisition, 10000 cells were collected for data analysis. Results expressed as mean percentage \pm SD of 6 mice per group. \# $p<0.05$ when each group is compared against baseline (day 0 ); ${ }^{*} p<0.05$ when $\gamma \mathrm{T} 3$ group is compared against vehicle group.

Figure 6. Percentage of (a) $C D 4^{+} T$-cells, (b) $C D 8^{+} T$-cells, (c) NK cells, and (d) Treg cell in peripheral blood analysed using a flow cytometer.

(a)

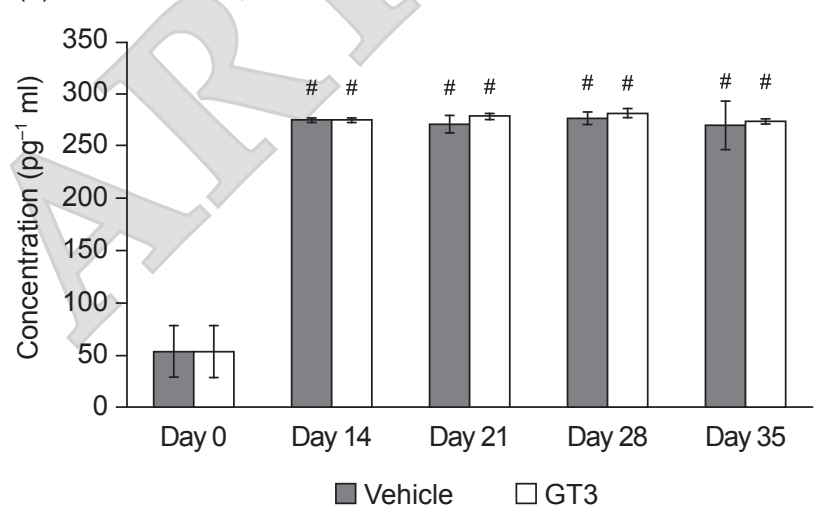

(b)

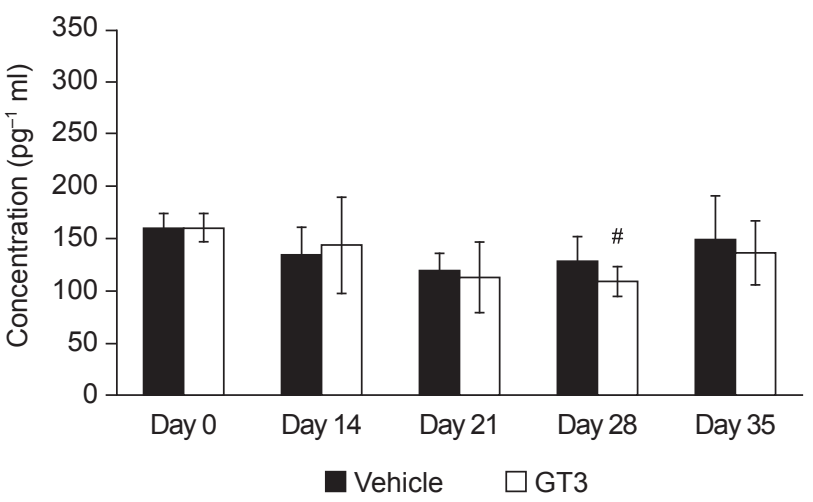

Note: Culture supernatant was harvested after $72 \mathrm{hr}$ and analysed for (a) IFN-g and (b) TGF- $\beta$ using commercial ELISA kits. Results expressed as mean percentage \pm SD of 6 mice per group. \# Significantly different $(p<0.05)$ from baseline (day 0 ).

Figure 7. Splenocytes obtained from spleens of mice fed with vehicle or $\gamma$ T3 (GT3)-fed mice cultured in the presence of mitomycin-C treated $4 T 1$ cells. 


\section{CONCLUSION}

This study shows that supplementing mice with $0.5 \mathrm{mg}$ twice daily with $\gamma \mathrm{T} 3$ showed promising results with regards to its anticancer effects based on the tumour growth and histopathology results. These findings suggest that $\gamma \mathrm{T} 3$ provided via the oral route has reached the breast tumour tissues and was able to exert some anticancer effects in this mouse model. However, $\gamma \mathrm{T} 3$ supplementation did not appear to have a significant effect on modulation of host immune system in this model.

\section{ACKNOWLEDGEMENT}

The authors would like to thank the International Medical University for providing the research facilities to carry out this study. This work was supported by a research grant from the Malaysian Palm Oil Board (MPOB) [PD167] and an FRGS grant (FRGS/1/2013/SG05/IMU/01/1). All the lab work carried out at International Medical University (IMU).

\section{REFERENCES}

Abdul Hafid, S R and Radhakrishnan, A K (2019). Palm tocotrienol-adjuvanted dendritic cells decrease expression of the SATB1 gene in murine breast cancer cells and tissues. Vaccines, 7(4): 198. DOI: $10.3390 /$ vaccines7040198.

Abdul Hafid, S R; Chakravarthi, S; Nesaretnam, K and Radhakrishnan, A K (2013). Tocotrienoladjuvanted dendritic cells inhibit tumor growth and metastasis: A murine model of breast cancer. PLoS ONE, 8(9): 74753. DOI: 10.1371/journal. pone.0074753.

Abdullah, NA; Mahiyuddin, W R W; Muhammad, N A; Ali, Z M; Ibrahim, L; Tamim, N S I; Mustafa, A N and Kamaluddin, M A (2013). Survival rate of breast cancer patients in Malaysia: A populationbased study. Asian Pac. J. Cancer Prev., 14(8): 45914594. DOI: 10.7314/ APJCP.2013.14.8.4591.

Abraham, A; Kattoor, A J; Saldeen, T and Mehta, J L (2019). Vitamin E and its anticancer effects. Crit. Rev. Food Sci. Nutr., 59(17): 2831-2838. DOI: 10.1080/10408398.2018.1474169.

Abuasal, B S; Qosa, H; Sylvester, P W and Kaddoumi, A (2012). Comparison of the intestinal absorption and bioavailability of $\gamma$-tocotrienol and $\alpha$-tocopherol: In vitro, in situ and in vivo studies. Biopharm. Drug Dispos., 33(5): 246-256. DOI: 10.1002 / bdd.1790.
Aggarwal, V; Kashyap, D; Sak, K; Tuli, H S; Jain, A; Chaudhary, A; Garg, V K; Sethi, G and Yerer, M B (2019). Molecular mechanisms of action of tocotrienols in cancer: Recent trends and advancements. Int. J. Mol. Sci., 20(3): 656. DOI: 10.3390 /ijms20030656.

Alizadeh, D; Wong, R A; Gholamin, S; Maker, M; Aftabizadeh, M; Yang, X; Pecoraro, J R; Jeppson, J D; Wang, D; Aguilar, B; Starr, R; Larmonier, C B; Larmonier, N; Chen, M-H; Wu, X; Ribas, A; Badie, B; Forman, S J and Brown, C E (2021). IFNg is critical for CAR $\mathrm{T}$ cell mediated myeloid activation and induction of endogenous immunity. Cancer Discov., 11(9): 2248-2265. DOI: 10.1158/2159-8290.CD-20-1661.

Azizah, A M; Hashimah, B; Nirmal, K; Siti Zubaidah, A R; Puteri, N A; Nabihah, A; Sukumaran, R; Balqis, B; Nadia, S M R; Sharifah, S S S; Rahayu, O; Nur Alham, O and Azlina, A A (2019). Malaysia National Cancer Registry Report (MNCR) (2012-2016). Ministry of Health, Putrajaya. p. 1-100.

Bray, F; Ferlay, J; Soerjomataram, I; Siegel, R L; Torre, L A and Jemal, A (2018). Global cancer statistics 2018: GLOBOCAN estimates of incidence and mortality worldwide for 36 cancers in 185 countries. CA: A Cancer J. Clinicians, 68(6): 394-424. DOI: 10.3322/ caac. 21492 .

De Silva, L; Chuah, L H; Meganathan, P and Fu, J Y (2016). Tocotrienol and cancer metastasis. Biofactors, 42(2): 149-162. DOI: 10.1002/biof.1259.

Fedchenko, N and Reifenrath, J (2014). Different approaches for interpretation and reporting of immunohistochemistry analysis results in the bone tissue - A review. Diagn. Pathol., 9(1): 221. DOI: 10.1186/s13000-014-0221-9.

Fontana, F; Raimondi, M; Marzagalli, M; Audano, M; Beretta, G; Procacci, P; Sartori, P; Mitro, N and Limonta, P (2020). Mitochondrial functional and structural impairment is involved in the antitumor activity of $\delta$-tocotrienol in prostate cancer cells. Free Radic. Biol. Med., 160: 376-390. DOI: 10.1016/j. freeradbiomed.2020.07.009.

Ghanem, P; Zouein, A; Mohamad, M; Hodroj, M H; Haykal, T; Abou Najem, S; Naim, H Y and Rizk, S (2019). The vitamin $\mathrm{E}$ derivative gamma tocotrienol promotes anti-tumor effects in acute myeloid leukemia cell lines. Nutrients, 11(11): 2808. DOI: $10.3390 /$ nu11112808.

Hafid, S R A; Radhakrishnan, A K and Nesaretnam, K (2010). Tocotrienols are good adjuvants for developing cancer vaccines. BMC Cancer, 10(1): 5. DOI: 10.1186/1471-2407-10-5. 
Huang, Y; Ma, C; Zhang, Q; Ye, J; Wang, F; Zhang, Y; Hunborg, P; Varvares, M A; Hoft, D F; Hsueh, E C and Peng, G (2015). CD4 ${ }^{+}$and $\mathrm{CD}^{+} \mathrm{T}$ cells have opposing roles in breast cancer progression and outcome. Oncotarget, 6(19): 17462-78. DOI: 10.18632 / oncotarget.3958.

Kabir, M I; Adnan, M and Rahman, M M (2017). Natural sources of tocotrienols: A note on absorption. J. In Silico In vitro Pharmacol, 3: 20. DOI: $10.21767 / 2469-6692.100020$.

Knochelmann, H M; Dwyer, C J; Bailey, S R; Amaya, S M; Elston, D M; Mazza-McCrann, J M and Paulos, C M (2018). When worlds collide: Th17 and Treg cells in cancer and autoimmunity. Cell. Mol. Immunol., 15(5): 458-469. DOI: 10.1038/s41423018-0004-4.

Maarasyid, C; Muhamad, I I and Supriyanto, E (2014). Potential source and extraction of vitamin E from palm-based oils: A review. Jurnal Teknologi, 69(4). DOI: $10.11113 /$ jt.v69.3172.

Mba, O I; Dumont, M J and Ngadi, M (2015). Palm oil: Processing, characterization and utilization in the food industry - A review. Food Biosci., 10: 26-41. DOI: $10.1016 /$ j.fbio.2015.01.003.

Medeiros, B and Allan, A L (2019). Molecular mechanisms of breast cancer metastasis to the lung: Clinical and experimental perspectives. Int. J. Mol. Sci., 20(9): 2272. DOI: 10.3390 /ijms20092272.

Mikami, N; Kawakami, R and Sakaguchi, S (2020). New Treg cell-based therapies of autoimmune diseases: Towards antigen-specific immune suppression. Curr. Opin. Immunol., 67: 36-41. DOI: 10.1016/j.coi.2020.07.004.

Montagnani Marelli, M; Marzagalli, M; Fontana, F; Raimondi, M; Moretti, R M and Limonta, P (2019). Anticancer properties of tocotrienols: A review of cellular mechanisms and molecular targets. J. Cell. Physiol., 234(2): 1147-1164. DOI: 10.1002/ jcp. 27075.

Nesaretnam, K; Selvaduray, K R; Abdul Razak, G; Veerasenan, S D and Gomez, P A (2010). Effectiveness of tocotrienol-rich fraction combined with tamoxifen in the management of women with early breast cancer: A pilot clinical trial. Breast Can. Res., 12(5): 1-8. DOI: $10.1186 /$ bcr2726.

Nesaretnam, K; Stephen, R; Dils, R and Darbre, P (1998). Tocotrienols inhibit the growth of human breast cancer cells irrespective of estrogen receptor status. Lipids, 33(5): 461-469. DOI: $10.1007 /$ s11745998-0229-3.
Nesaretnam, K; Guthrie, N; Chambers, A F and Carroll, K K (1995). Effect of tocotrienols on the growth of a human breast cancer cell line in culture. Lipids, 30(12): 1139-1143. DOI: 10.1007 / BF02536615.

Ohue, Y and Nishikawa, H (2019). Regulatory $\mathrm{T}$ (Treg) cells in cancer: Can Treg cells be a new therapeutic target? Cancer Sci., 110(7): 2080-2089. DOI: $10.1111 /$ cas.14069.

Ording, A G; Heide-Jørgensen, U; Christiansen, C F; Nørgaard, M; Acquavella, J and Sørensen, H T (2017). Site of metastasis and breast cancer mortality: A Danish nationwide registry-based cohort study. Clin. Exp. Metastasis, 34(1): 93-101. DOI: 10.1007 / s10585-016-9824-8.

Panneerselvam, J; Srivastava, A; Mehta, M; Chen, A; Zhao, Y D; Munshi, A and Ramesh, R (2019). IL-24 inhibits lung cancer growth by suppressing GLI1 and inducing DNA damage. Cancers, 11(12): 1879. DOI: $10.3390 /$ cancers 11121879 .

Pulaski, B A and Ostrand-Rosenberg, S(2000). Mouse 4T1 breast tumor model. Curr. Protoc. Immunol., 39(1): 20.2.1-20.2.16. DOI: 10.1002/0471142735. im2002s39.

Rzepecka, A; Żmigrodzka, M; WitkowskaPiłaszewicz, O; Cywińska, A and Winnicka, A (2019). CD4 and MHCII phenotypic variability of peripheral blood monocytes in dogs. PLoS ONE, 14(7): e0219214. DOI: 10.1371/journal. pone.0219214.

Sazli, F A R; Jubri, Z; Rahman, M A; Karsani, S A; Top, A G M and Ngah, W Z W (2015). Gammatocotrienol treatment increased peroxiredoxin-4 expression in HepG2 liver cancer cell line. BMC Complement Altern. Med., 15(1): 64. DOI: 10.1186/ s12906-015-0590-y.

Sambucci, M; Gargano, F; Guerrera, G; Battistini, L and Borsellino, G (2019). One, no one, and one hundred thousand: T regulatory cells' multiple identities in neuroimmunity. Front. Immunol., 10: 2947. DOI: 10.3389/ fimmu.2019.02947.

Sasidharan Nair, V and Elkord, E (2018). Immune checkpoint inhibitors in cancer therapy: A focus on T-regulatory cells. Immunol. Cell Biol., 96(1): 21-33. DOI: 10.1111 / imcb.1003.

Selvaduray, K R; Radhakrishnan, A K; Kutty, M K and Nesaretnam, K (2012). Palm tocotrienols decrease levels of pro-angiogenic markers in human umbilical vein endothelial cells (HUVEC) and murine mammary cancer cells. Genes Nutr., 7(1): 53-61. DOI: 10.1007 / s12263-011-0223-0. 
Selvaduray, K R; Radhakrishnan, A K; Kutty, M K and Nesaretnam, K (2010). Palm tocotrienols inhibit proliferation of murine mammary cancer cells and induce expression of interleukin-24 mRNA. J. Interferon Cytokine Res., 30(12): 909-916. DOI: $10.1089 /$ jir.2010.0021.

Shaharudin, S H; Sulaiman, S; Emran, N A and Shahril, M R (2011). The use of complementary and alternative medicine among Malay breast cancer survivors. Alt. Ther. Health Med., 17(1): 50.

Srivastava, J K and Gupta, S (2006). Tocotrienolrich fraction of palm oil induces cell cycle arrest and apoptosis selectively in human prostate cancer cells. Biochem. Biophys. Res. Commun., 346(2): 447453. DOI: $10.1016 /$ j.bbrc.2006.05.147.

Subramaiam, H; Chu, W L; Radhakrishnan, A K; Chakravarthi, S; Selvaduray, KR and Kok, YY (2021). Evaluating anticancer and immunomodulatory effects of spirulina (Arthrospira) platensis and gamma-tocotrienol supplementation in a syngeneic mouse model of breast cancer. Nutrients, 13(7): 2320. DOI: $10.3390 /$ nu13072320.

Tanaka, A and Sakaguchi, S (2019). Targeting Treg cells in cancer immunotherapy. Eur. J. Immunol., 49(8): 1140-1146. DOI: 10.1002/ eji.201847659.

Verma, A; Mathur, R; Farooque, A; Kaul, V; Gupta, S and Dwarakanath, B S (2019). T-regulatory cells in tumor progression and therapy. Cancer Manag. Res., 11: 10731-10747. DOI: 10.2147 / CMAR.S228887.

Wada, S; Naito, Y; Matsushita, Y; Nouchi, M; Kawai, M; Minami, E; Aoi, W; Ikeda, S; Higashi, A and Yoshikawa, T (2017). $\delta$-tocotrienol suppresses tumorigenesis by inducing apoptosis and blocking the COX-2 / PGE2 pathway that stimulates tumor- stromal interactions in colon cancer. J. Funct. Foods, 35: 428-435. DOI: 10.1016/j.jff.2017.06.002.

Weng-Yew, W; Selvaduray, K R; Ming, C H and Nesaretnam, K (2009). Suppression of tumor growth by palm tocotrienols via the attenuation of angiogenesis. Nutr. Cancer, 61(3): 367-373. DOI: $10.1080 / 01635580802582736$.

Wu, S J and Ng, L T (2010). Tocotrienols inhibited growth and induced apoptosis in human HeLa cells through the cell cycle signaling pathway. Integr. Cancer Ther., 9(1): 66-72. DOI: $10.1177 / 1534735409357757$.

Yamamoto, K; Kobayashi, H; Miura, O; Hirosawa, S and Miyasaka, N (1997). Assignment (a) of IL12RB1 and IL12RB2, interleukin-12 receptor (beta) 1 and (beta) 2 chains, to human chromosome 19 band p13. 1 and chromosome 1 band p31. 2, respectively, by in situ hybridization. Cytogenet. Cell Genet., 77(34): 257-258. DOI: $10.1159 / 000134589$.

Yu, N; Li, X; Song, W; Li, D; Yu, D; Zeng, X; Li, M; Leng, $X$ and Li, $X$ (2012). CD4 ${ }^{+}$CD25 $5^{+}$CD127 low /T cells: A more specific Treg population in human peripheral blood. Inflammation, 35(6): 1773-1780. DOI: 10.1007 / s10753-012-9496-8.

Zhang, Y; Liu, Y and Xu, Y (2019). Interleukin-24 regulates $\mathrm{T}$ cell activity in patients with colorectal adenocarcinoma. Front. Oncol., 9: 1401. DOI: 10.3389 / fonc. 2019.01401 .

Zhang, Y H; Ma, K; Liu, J R; Wang, H X; Tian, W X; Tu, Y H and Sun, W G (2018). $\gamma$-tocotrienol inhibits the invasion and migration of human gastric cancer cells through downregulation of cyclooxygenase-2 expression. Oncol. Rep., 40(2): 999-1007. DOI: 10.3892 / or.2018.6497. 